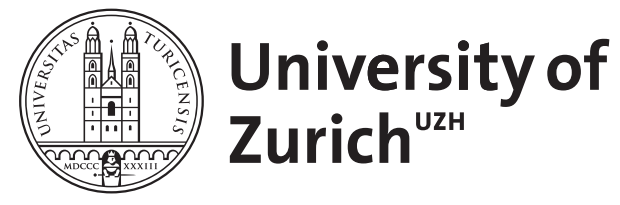

\title{
Age determination of arianta arbustorum (L.) (Pulmonata) Based on growth breaks and inner layers
}

\author{
Raboud, Christian
}

\begin{abstract}
The pulmonate snail Arianta arbustorum from the Swiss Alps was aged using thin sections of the shell margins cut from marked individuals. Shell layers at the apertural lip and growth breaks in the juvenile can give a reliable estimate of age
\end{abstract}

DOI: https://doi.org/10.1093/mollus/52.3.243

Posted at the Zurich Open Repository and Archive, University of Zurich ZORA URL: https://doi.org/10.5167/uzh-154227

Journal Article

Published Version

Originally published at:

Raboud, Christian (1986). Age determination of arianta arbustorum (L.) (Pulmonata) Based on growth breaks and inner layers. Journal of Molluscan Studies, 52(3):243-247.

DOI: https://doi.org/10.1093/mollus/52.3.243 


\title{
AGE DETERMINATION OF ARIANTA ARBUSTORUM (L.) (PULMONATA) BASED ON GROWTH BREAKS AND INNER LAYERS
}

\author{
CHRISTIAN RABOUD \\ Zoological Museum, University of Zürich-Irchel, Winterthurerstr. 190, CH-8057 Zürich, Switzerland
}

(Received 16 May 1986)

\begin{abstract}
The pulmonate snail Arianta arbustorum from the Swiss Alps was aged using thin sections of the shell margins cut from marked individuals. Shell layers at the apertural lip and growth breaks in the juvenile can give a reliable estimate of age.

\section{INTRODUCTION}

Shell increments have been successfully used to demonstrate growth rates and ageing of marine bivalves (Pannella \& McClintock, 1968; Rhoads \& Lutz, 1980). Comparable data on land pulmonates are not readily applicable, because these are based on the maximum ages attained under diverse environmental conditions rather than on exact age determinations or distributions (Taylor, 1914; Comfort, 1957). In adult Cepaea age has been estimated from periostracum wear (Goodhart, 1962; Williamson, 1975, 1976; Williamson, Cameron \& Carter 1977 ) and from relative shell weight (Williamson, 1979). Pollard $(1973,1975,1977)$ and Falkner (1984) have suggested, that the layerings of the lip of Helix pomatia are formed annually. Similarly this paper shows that the layerings at the inner side of the lip of adult Arianta arbustorum and the growth breaks in the juvenile and subadult phase are formed annually. This provides a method by which the age structure of populations of Arianta arbustorum living in the Alps can be determined with reasonable accuracy (Raboud, 1985).
\end{abstract}

\section{METHODS}

The methods of age assessment described in this paper are based on winter growth breaks and inner layers.
In the woods of the Swiss Midlands, the shells of Arianta are usually large $(20-25 \mathrm{~mm})$ and brown, and on mountain slopes and alpine meadows small (12$15 \mathrm{~mm}$ ) and yellowish (Burla \& Stahel, 1983). The winter breaks are more easily seen on darker than on lighter shells. This is specially true for the whorls near the apex. However the winter breaks on paler shells can be recorded if empty, wet shells are held in a cold light source. By choosing a suitable incidence of the light the winter breaks appear as dark thin lines (Fig. 1).

In order to identify and count the number of inner layerings laid per year under natural conditions thin sections were cut from snails, which had been marked for an experiment as subadults in September 1981 and which were recovered in July 1984.

To cut thin sections, the snails are first frozen at $-20^{\circ} \mathrm{C}$. After thawing, the body can easily be picked out with forceps. The shells are then cut in half vertically to the coiling axis two to three milimeters behind the lip. Depending on the shell size, five to ten such fragments are put in a polyethylene cup which is $25.5 \times 18 \mathrm{~mm}$ in size and kept upright with plastilin one behind the other. Following this, the fragments in the cups are embedded in transparent cement (AKEMI), (Louis Bettler AG, CH-5445 Eggenwil AG). The cement blocks are finally fixed on a LEITZ saw microtome 1600 and cut to $50 \mu \mathrm{m}$ thin sections.

The surface of the sections is smooth, so that further processing is unnecessary. The cuts are glued with cyanoacrylat on a cover slide to prevent the sections from breaking by the cooling water and the centrifugal force. Embedded in Eukitt on a microscope slide the sections can then be viewed and analysed under a phase contrast microscope. The built-in rotatable polarisation filters make it possible to distinguish the layers optically. The ostracum is thicker at the lip than further on along the shell (Figs 2 and 3 ). The layerings were therefore counted towards the posterior edge of the lateral lip close to the bases. In order to allow an exact determination of the number of layers, three to five thin sections were cut from each snail, independently analysed and finally compared. 


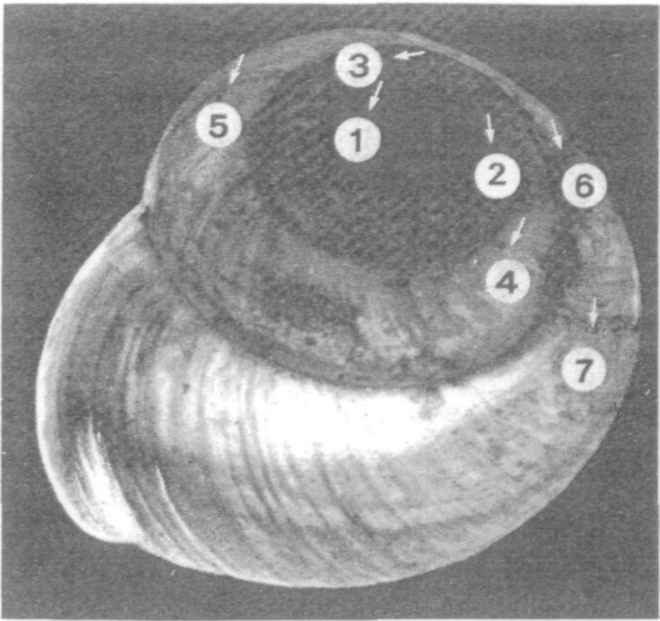

Fig. 1. Growth breaks seen on a shell from an altitude of $2500 \mathrm{~m}$ using a cold light source. The breaks 1 and 3 are not discernible under this incidence of light.

\section{RESULTS}

As in species of Cepaea (Richardson, 1975; Wolda, 1970a; Oosterhoff, 1977), Arianta arbustorum requires several years to reach maturity depending on its geographic position. Growth is interrupted between autumn and spring. The snails bridge these periods by hibernating. In the Swiss Midlands Arianta arbustorum comes out of hibernation at the end of March. The yearly growth break of the juvenile and subadult phase appears on the shell surface as a light continuous strip or as a narrow line (i.e. Terhivuo, 1978) as in the species of Cepaea (Wolda, $1970 \mathrm{~b}$ ). The presence of this strip is further indicated if the midband is dissolved or missing. Apart from the winter breaks, there is another type of growth break, which however, is only faintly marked off by a small line on the shell surface; this could result from aestivation during dry warm periods or a period of rest during spawning. These two growth breaks can be used to establish exactly in years the subadult age of a snail.

In the species of Arianta, the shell continues growing till maturity. Adult snails can be recognized by the raised lip. With advancing age, the ostracum of old specimens thickens by inner increments, especially at the lip. These are evident under the light microscope as layers (Fig. 4). All snails which had been marked as subadults in 1981 and found again in September 1984 showed three layers at the inner side of the lip (Fig. 5). These layers correspond to the three years of the adult phase, each layer representing one year. The older the snail, the thicker is the lip, the shell colour is lighter and the shell surface, between the lateral lip bases is whiter. The age of the snail can easily be assessed by counting the number of winter breaks and adding this to the yearly increments.

\section{DISCUSSION}

For perennial helicids with a determinate growth

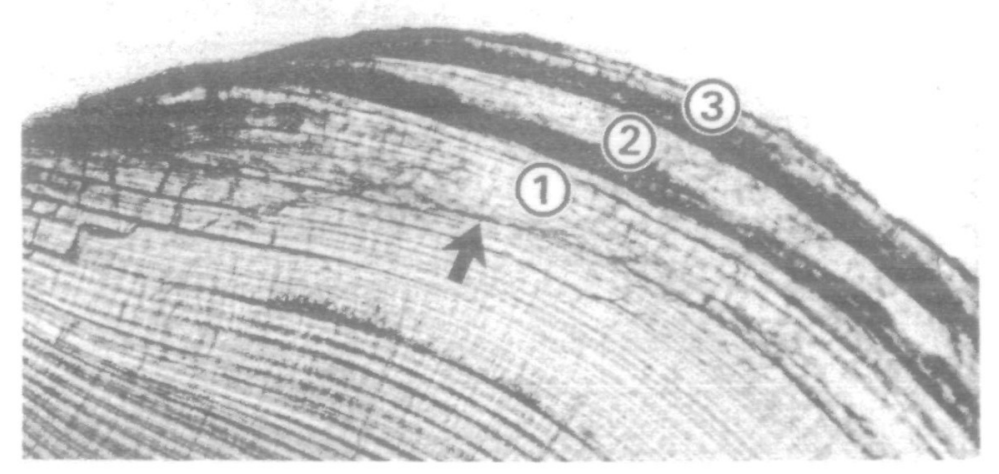

Fig. 2. Thin section of a shell sampled near Zürich. The layers 1 to 3 taper off right behind the lip $(\times 10)$. 


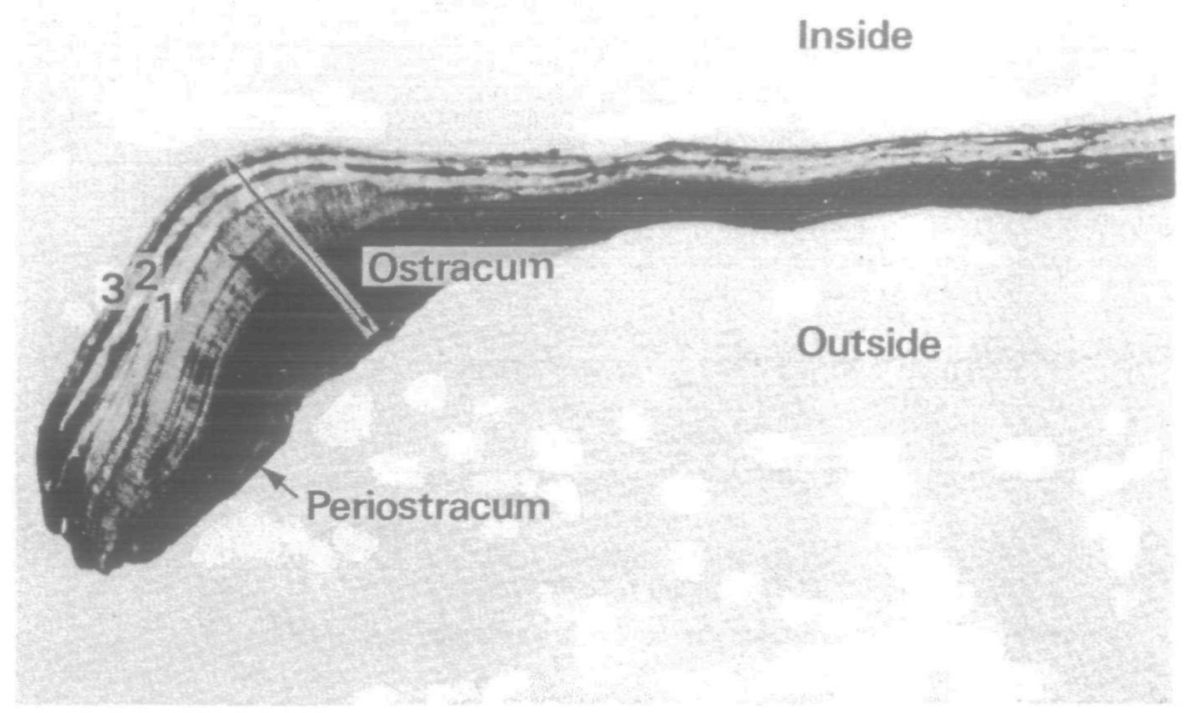

Fig. 3. Selective enlargement of the same shell as in Fig. 2 about one centimeter behind the lip. The increments are infused and no longer discernible as single layers $(\times 18)$.

like Arianta, the only reliable age assessment based on shell features is provided by the two methods mentioned above. The ring-method in which the counts of the seasonal growth breaks are counted can only be applied to snails with indeterminate growth (Comfort, 1957).

Shell growth classes in Arianta are reliable in the subadult phase. As pointed out by Haskin (1954) size frequency distributions need careful interpretation. Their usefulness stops with adulthood. Moreover, estimation errors may arise in the subadult phase with overlapping generations and small numbers, so that the age of the smaller year classes may therefore be unknown. In species which continue to grow for life the inaccuracy is reduced, but older, slowgrowing age classes cannot be distinguished (Wilbur \& Owen, 1964). In a recent study (Falkner, 1984) on Helix pomatia dark inclusions at the lip are interpreted as remnants of earlier winter epiphragms. Similar dark spots can be seen in thin sections of Arianta, but as it

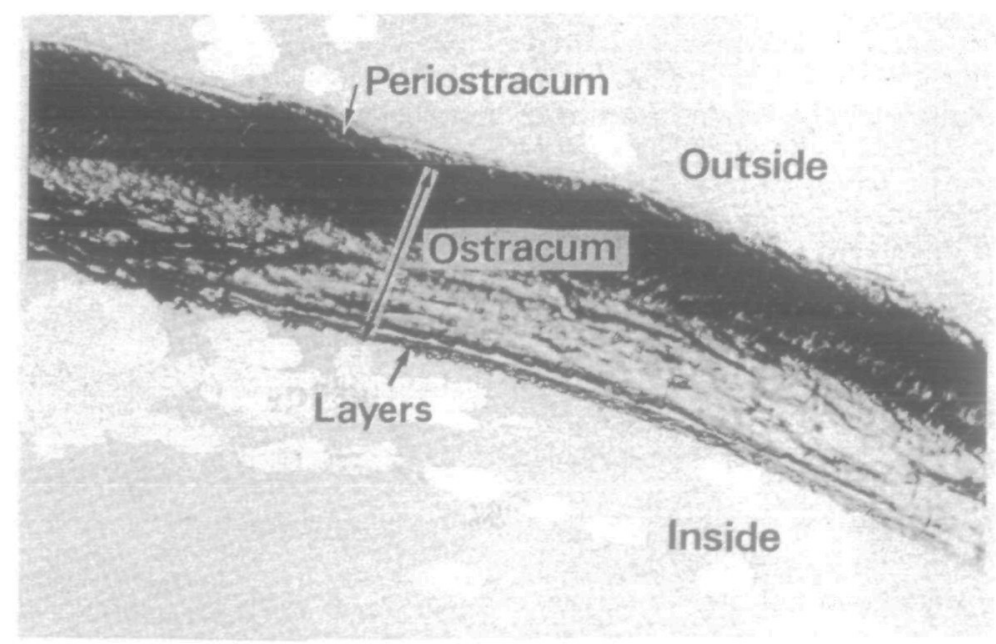

Fig. 4. Thin section of a shell from an altitude of $2215 \mathrm{~m}$ with six layers $(\times 130)$. 


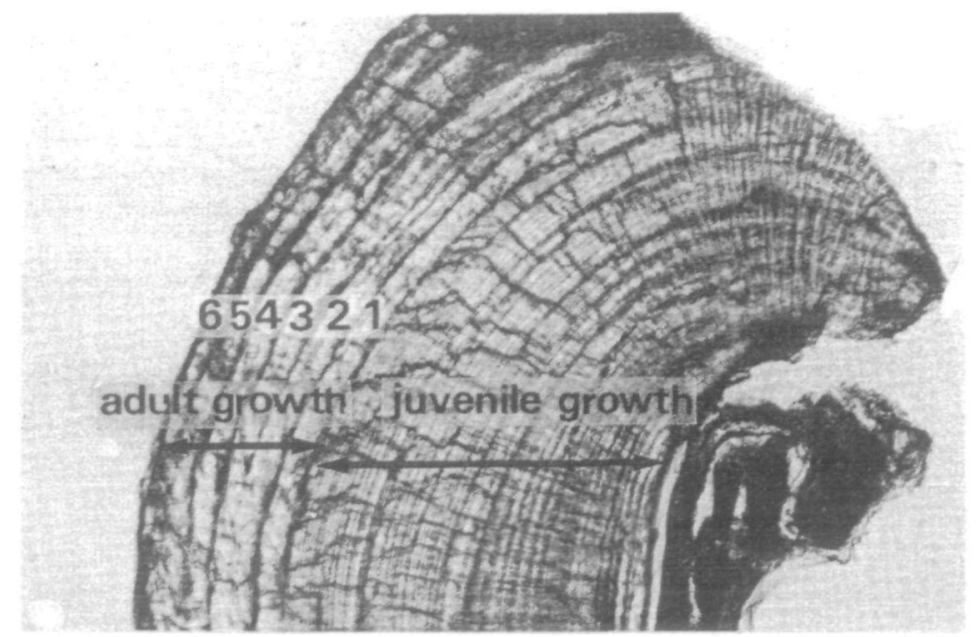

Fig. 5. Thin section of a shell from the Swiss Midlands which was marked as an subadult in September 1981 and refound during the summer 1984. Three layers are visible. The arrow indicates the delimitation between the subadult and adult growth phase $(\times 165)$.

does not build a real epiphragm for hibernation, only a transparent skin, the use for ageing needs to be investigated. An age estimation based on periostracum wear (Goodhart, 1962; Williamson, 1975, 1976) is only possible if the locality is homogeneous. Comparisons between different populations are not possible, because within the same population the area is never homogeneous. The shell is submitted to different types of wear in the snail's home range.

The methods described above demonstrate again that life-spans in molluscs have long been underestimated. Ages of more than a hundred years are not rare in deep-sea shells (Rhoads \& Lutz, 1980). In the land mollusc Helix pomatia individuals were found to be more than thirty years old (Falkner, 1984). Even specimens of the smaller Arianta arbustorum living at 2500 masl may be 17 years old (Raboud, in prep.). Since the two helicids Arianta arbustorum and Cepaea $s p$. have approximately the same size and occupy similar areas, it is supposed that Cepaea sp. at its altitudinal distribution limit at 1600 masl reaches an age of ten years similar to Arianta arbustorum. Thin sections of shells of Cepaea hortensis have also shown layers (Raboud, unpublished). If these layers correspond to those of Arianta, many existing problems could be solved and part of the alreadyexisting work on Cepaea sp. could be evaluated on the basis of age.

\section{ACKNOWLEDGEMENTS}

I thank J. Camilleri and G. Ribi for their comments on an earlier draft of the manuscript; $H$. Arter for useful discussions and the assistance in improving the methods.

\section{REFERENCES}

Burla, H. \& W. STAhel, 1983. Altitudinal variation in Arianta arbustorum (Mollusca, Pulmonata) in the Swiss Alps. Genetica, 62, 95-108.

COMFORT, A. 1957. The duration of life in molluses. Proceedings of the Malacological Society of London 32, 219-241.

FALKNER, G. 1984. Das bayerische Weinbergschnecken-Projekt (Untersuchungen an Helix pomatia L.) Mitteilungen der deutschen malakologischen Gesellschafi, 37, 182-197.

GOODHART, C.B. 1962. Variation in a colony of the snail Cepaea nemoralis. Journal of Animal Ecology 31, 207-237.

Haskin, H.H. 1954. Age determination in molluses. Transactions of the New York Academy of Sciences 16, Series 2, 300-304.

OOSTERHOFF, L.M. 1977. Variation in growth rate as an ecological factor in the landsnail Cepaea nemoralis (L.) Netherlands Journal of Zoology 27, $1-132$.

Pannella, G. \& MacClintock, C. 1968. Biological and environmental rhythms reflected in molluscan shell growth. Journal of Paleontology, 42, 64-80. 
POLLARD, E. 1973. Growth classes in the adult Roman snail (Helix pomatia L.). Oecologia 12, 209-212.

POLLARD, E. 1975. Aspects of the ecology of Helix pomatia L. Journal of Animal Ecology 44, 305-329.

POLLARD, E., COOKE, A.S. \& WelCh, J.M. 1977. The use of shell features in age determination of juvenile and adult Roman snails Helix pomatia. Journal of Zoology, London. 183, 269-279.

RABOUD, C. 1985. Demographische Altersverteilung bei Arianta arbustorum (Mollusca, Pulmonata) in Abhängigkeit von der Höhe über Meer. Dissertation Universität Zürich.

RHOADS, D.C. \& LUTZ, R.A. 1980 Skeletal growth of aquatic systems, Biological records of environmental change, Plenum Press, New York, pp. 740

Rhoads, D.C. \& PanNella, G. 1970. The use of molluscan shell growth patterns in ecology and paleoecology. Lethaia, 3, 143-161.

RICHARDSON, A.M.M. 1975. Energy flux in a natural population of the land snail, Cepaea nemoralis $\mathrm{L}$. Oecologia, 19, 141-164.

TAYLOR, J.W. 1914. Monograph of the land and freshwater mollusca of the British Isles. Vol. III. Zonitidae, Endodontidae and Helicidae. Leeds: Taylor Brothers.

TERHIVUo, J. 1978. Growth, reproduction and hibernation of Arianta arbustorum (L.) (Gastropoda,
Helicidae) in southern Finland. Annales Zoologici Fennici, 15, 8-16.

WILBUR, K.M. \& OWEN, G. 1964. Growth. In: Physiology of Mollusca, Vol 1, (Eds. K.M. Wilbur, and C.M. Yonge), pp. 211-242. Academic Press, New York and London.

Williamson, P. 1975. The feeding ecology and energetics of a grassland population of the snail Cepaea nemoralis L. Unpublished Ph.D. thesis, Portsmouth Polytechnic.

WILLIAMSON, P. 1976. Size-weight relationships and field growth rates of the landsnail Cepaea nemoralis L. Journal of Animal Ecology 45, 875-885.

WILLIAMSON, P. 1979. Age determination of juvenile and adult Cepaea. Journal of Molluscan Studies 45, $52-60$.

Williamson, P., Cameron, R.A.D. \& Carter, M.A. 1977. Population dynamics of the landsnail Cepaea nemoralis L.: a six-year study. Journal of Animal Ecology 46, 181-194.

WOLDA, H. 1970a. Variation in growth rate in the landsnail Cepaea nemoralis. Researches on Population Ecology 12, 185-204.

WOLDA, H. 1970b. Ecological variation and its implication for the dynamics of populations of the landsnail Cepaea nemoralis. In: Dynamics of Numbers, (Eds. P.J. den Boer \& G.R. Gradwell), p. 98108, Wageningen, Pudoc. 